DOI: 10.35784/IAPGOS.244

\title{
DETERMINATION OF YOUNG'S DYNAMIC MODULUS OF POLYMER MATERIALS BY RESONANCE VIBRATING-REED METHOD
}

\author{
Volodymyr Mashchenko ${ }^{1}$, Valentine Krivtsov ${ }^{2}$, Volodymyr Kvasnikov $^{3}$, Volodymyr Drevetskiy $^{4}$ \\ ${ }^{1}$ Odessa State Academy of Technical Regulation and Quality, Department of Metrology and Metrological Support, Odessa, Ukraine, ${ }^{2}$ Rivne State Humanitarian University, \\ Department of Physics, Rivne, Ukraine, ${ }^{3}$ National Aviation University, Department of Computerized Electrical Systems and Technologies, Kiev, Ukraine, ${ }^{4}$ National University \\ of Water and Environmental Engineering, Department of Automation, Electrotechnical and Computer-integrated Technologies, Rivne, Ukraine
}

Abstract. The paper deals with its own oscillations of a rectangular rod with a cross section of a rectangular shape. The method of determining real part of Young's dynamic modulus and tangent of mechanical loss of samples in the form of rods of a number of polymer materials by means of resonant vibrating-reed method are proposed. Experimental setup, algorithm and software for determining the amplitude of the sample oscillations are developed. The accuracy of measurements was determined and a comparative analysis of results was performed with data obtained by other methods.

Keywords: oscillation amplitude, frequency measurements, acoustic and viscoelastic properties

\section{OKREŚLENIE DYNAMICZNEGO MODULU YOUNGA MATERIAŁÓW POLIMEROWYCH ZA POMOCĄ REZONANSOWEJ METODY WIBRACYJNEJ}

Streszczenie. W pracy opisano wahania własne prostokatnego sworznia o przekroju prostokątnym. Zaproponowano metode wyznaczenia za pomoca metody rezonansowej wibracyjnej rzeczywistej części dynamicznego modułu Younga i tangensa kata mechanicznych strat wzorców w postaci sworzniów z szeregu materiałów polimerowych. Opracowano eksperyment, algorytm i oprogramowanie dla określenia amplitudy wahań wzorca. Określono precyzję pomiarów i przeprowadzono porównawcza analizę wyników z rezultatami otrzymanymi innymi metodami pomiarów.

Słowa kluczowe: amplituda oscylacji, pomiary częstotliwości, właściwości akustyczne i lepkosprężyste

\section{Introduction}

Requirements for reducing the mass of structures operating in the same dynamic fields of stresses that occur during impulse loading due to polymer materials are an urgent task of modern professional equipment making. However, an important factor is to determine the physical and mechanical properties of such structural materials with high reliability of results. The elastic properties of polymer material are determined by the speeds of propagation of ultrasonic waves, the deformation properties at high deformation rates, and the relaxation characteristics at short time intervals. The experimental values of Young's modulus $(E)$ will be fully reliable only when obtained from wave-based and quasi-static experiments corresponding to the loading time of the order of a few microseconds - time of passing of the ultrasonic pulse through a polymer material sample. The results of mechanical tests using resonance methods that correspond to time intervals in the millisecond range can be used to refine or complement each other at such relatively high time intervals. Resonance methods in different modifications are often used to define Young's modules in PVC materials $[1-3,5,7]$. However, they do not always ensure essential accuracy or require additional theoretical calculations [8]. Therefore, new methods development or renovation of already existing ones are rather a pertinent issue.

\section{Resonance method for determining dynamic modulus of elasticity and mechanical loss factor}

Young's complex dynamic modulus $\left(E^{*}\right)$ and tangent of mechanical losses $(\operatorname{tg} \delta)$ of a number of polymer materials, the method of forced resonant oscillations of a fixed sample was used as a rod of rectangular shape at sound frequencies $[1,2]$.

The essence of method is to measure oscillation amplitude $(A)$ of free end of the rod when changing frequency of driving force applied to the other fixed end. According to $|A|$ sample measurements of transverse oscillations at different frequencies, a resonance curve is constructed, which parameters are frequency of oscillations $(f)$ and ratio of amplitudes $\left(|A| /\left|A_{\text {max }}\right|\right)$, where $A_{\max }$ is the maximum value of the amplitude corresponding to principal resonant frequency $\left(f_{r}\right)$. For $f_{r}$ determines the width of resonance curve $\left(\Delta f_{r}\right)$ at the level $\frac{\left|A_{\max }\right|}{\sqrt{2}}$.
The behaviour of a sample of a polymer material (Fig. 1) during oscillations under the disturbing force is described by the following differential equation [4]:

$$
\rho \frac{\partial^{2} u(x, t)}{\partial t^{2}}+E^{*} \chi^{2} \frac{\partial^{4} u(x, t)}{\partial x^{4}}=0,
$$

where $u(x, t)$ is function of dependence of points transverse displacements of the rod axis on coordinate $x$ and time $t ; \rho$ is the density of polymer material.

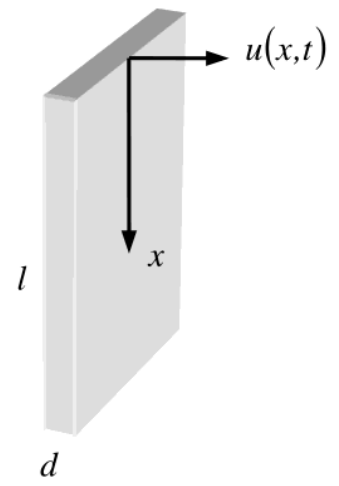

Fig. 1. Specimen and its vibrating coordinate system

The solution of equation (1) is represented as a harmonic function

then, we get

$$
u(x, t)=X(x) e^{i \omega t},
$$

$$
\frac{d^{4} X(x)}{d x^{4}}+k X(x)=0,
$$

where $k^{*}$ complex wave number of oscillations per bend; where $\omega$ cyclic frequency ( $\omega=2 \pi f$ ).

The general solution of equation (3) is as follows

$$
X(x)=A_{1} \cos k x+A_{2} \sin k x+A_{3} \operatorname{ch} k x+A_{4} \operatorname{sh} k x,
$$

where $A_{i}$ arbitrary constants.

The boundary conditions for our problem are as follows

$$
\begin{aligned}
& X(0)=X^{\prime}(0)=0 ; \\
& X^{\prime \prime}(l)=X^{\prime \prime \prime}(l)=0 .
\end{aligned}
$$

where $l$ is the sample length. 
The integral of equation (3) satisfying the conditions at the end $x=0$ has following form:

$$
X(x)=\frac{1}{2} A_{3}(\operatorname{chk} x-\cos k x)+\frac{1}{2} A_{4}(\operatorname{sh} k x-\sin k x),
$$

The conditions at end $x=l$ are expressed by the following equations

$$
A_{3}(\operatorname{chkl}+\cos k l)+A_{4}(\operatorname{shkl}+\sin k l)=0
$$

where

$$
\left(\operatorname{chk}^{*} l+\cos k^{*} l\right)^{2}-\left(\operatorname{sh}^{2} k^{*} l-\sin ^{2} k^{*} l\right)=0,
$$

or

$$
\operatorname{chk}^{*} l \cos k^{*} l+1=0 .
$$

Putting $k^{*} l=a+i b$ at resonance of the rod in conditions of $a=a_{i} ; b=0$, enables to obtain a ratio for the sample amplitude oscillations

$$
X_{i}(x)=C\left(\operatorname{ch} a_{i} x-\cos a_{i} x-\frac{\left(\operatorname{sh} a_{i} x-\sin a_{i} x\right)^{2}}{\operatorname{ch} a_{i} x+\cos a_{i} x}\right),
$$

where $a_{i}$ roots of the equation (9), $C$ some constant.

The values $a$ and $b$ are defined as follows

$$
\begin{gathered}
a \cong \frac{\omega^{\frac{1}{2}} l}{\left(\frac{E \chi^{2}}{\rho}\right)^{\frac{1}{4}}} \\
b \cong \frac{1}{4} \frac{\omega^{\frac{1}{2}} l}{\left(\frac{E \chi^{2}}{\rho}\right)^{\frac{1}{4}}} \operatorname{tg} \delta
\end{gathered}
$$

moreover, for a rectangular rod $\chi=\frac{d}{\sqrt{12}}, d$ is the thickness of the sample.

The first four roots of equation

$$
k l=1,8751 ; \quad 4,6941 ; 7,8548 ; 10,9965 .
$$

In this case, at fundamental resonant frequency $f_{r}$, which corresponds to the smallest root of equation (9), we obtain following relation for $E^{\prime}$

$$
E^{\prime}=\frac{48 \pi^{2} \rho l^{4} f_{r}^{2}}{1,8751^{4} d^{2}} .
$$

For the value of $\operatorname{tg} \delta$ we have

$$
\operatorname{tg} \delta=\frac{\Delta f_{r}}{f_{r}} .
$$

Accordingly, imaginary part $\left(E^{\prime \prime}\right)$ of complex $E^{*}$ is defined as follows

$$
E^{\prime \prime}=E^{\prime} \operatorname{tg} \delta
$$

In this case, we can determine value of $E^{*}$ in the following way:

$$
E^{*}=\left(E^{2}+E^{\prime \prime 2}\right) \frac{1}{2}
$$

\section{Experimental setup and measurement technique}

Measurement $A$ for the construction of resonance curves and determination of $f_{r}$ was performed on installation, a block diagram which is shown in Fig. 2.

In experimental setup, a sample of polymer material 4 is placed into an air heat chamber 2 where it is rigidly fixed at one end to the thrust of mechanical oscillator 4 by means of a clamp. Thermal camera has viewing windows for optical observation of amplitude oscillations of closed and free ends of sample. In the middle of cameras a light-emitting diode backlight is placed. Mechanical oscillation of the sample is performed by field-relay, which is supplied from generator of audio frequency range 1 (Siglent SDG1010). The sample oscillation amplitude clamped end is governed by generator output voltage. In order to eliminate effects of power supply voltage fluctuations, a sound generator is connected via a ferroresonance voltage stabilizer.

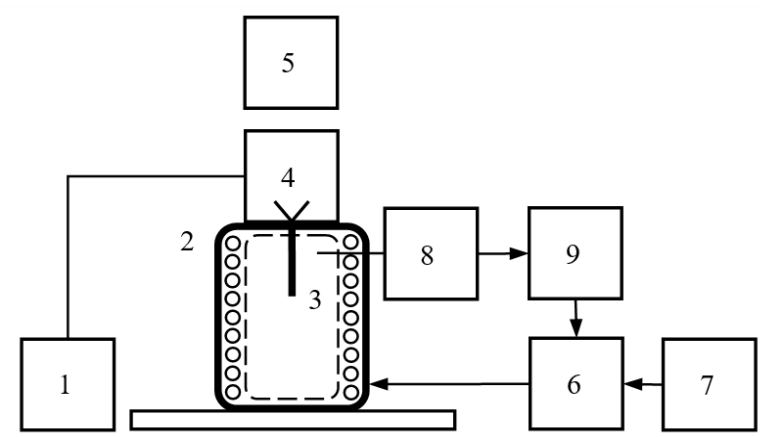

Fig. 2. Installation block diagram to study viscoelastic properties of polymer materials via resonance method

Measurement of resonance oscillations amplitude can be carried out at different temperatures of polymer sample to the glass transition temperature. Heating of camera is electric provided by auto-transformer 7 through solid-state Crydom H12D4825 6. Temperature mode in thermal chamber is supported by means of thermal sensor 8 and microprocessor controller 9 MTP-8. To determine amplitude of oscillations $A$ special software is developed that recognizes image of the sample oscillation using webcam 5 with an optical zoom.

Using oscillator, $f$ changes the sample oscillations in range of $10-140 \mathrm{~Hz}$ in $0.5 \mathrm{~Hz}$ increments and determine $A$.

\subsection{Algorithm for determining sample amplitude oscillations using software}

Using program interface (Fig. 3), two vertical and one horizontal lines define the sample oscillation region.

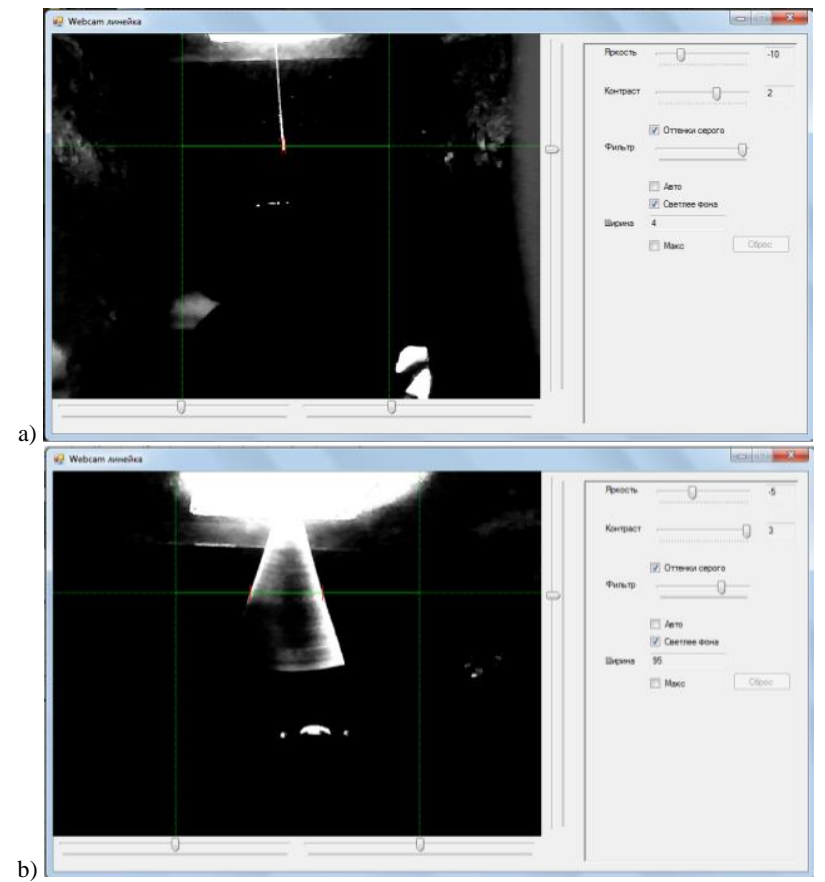

Fig. 3. Program interface used to determine sample oscillation amplitude from an image of an installation web camera to study resilient properties of polymer materials 
The program that automatically determines brightness threshold as an average brightness of points on a horizontal segment. By comparing brightness of two adjacent pixels, the program independently searches limits of sample oscillations. If brightness of $i$ pixel is lower than specified brightness threshold, and brightness of $i+1$ pixel is higher than brightness threshold, then we obtain left limit of oscillation, conversely, if $i+1$ pixel is darker than brightness threshold, and - lighter than this threshold, we get right limit of oscillation.

The program constantly compares determined left limit of oscillation with previously found one, selects the far left, coordinate of which is smaller relatively to vertical zero position. The obtained right boundary is also compared with the previously found boundary, and the extreme right is chosen, coordinate of which is larger relatively to vertical zero position. Magnitude of the sample oscillation will be automatically determined by the program and equal to $2 \mathrm{~A}$.

An optical zoom webcam allows you to zoom in on a sample 10 times. In this case, measurement error $A$ does not exceed $2 \%$

\section{Results and discussion}

Experimental studies were performed on polymer samples of polyvinyl chloride (PVC), polystyrene (PS), high density polyethylene (HDPE) and low density polyethylene (LDPE).
Density of polymer materials was determined by hydro-static weighing. According to the latter, $\rho$ sample immersed in thermostatic fluid will be determined as follows

$$
\rho=\frac{m}{m-m_{1}}\left(\rho_{1}-\rho_{2}\right)+\rho_{2} .
$$

where $m, m_{1}-$ mass of sample in air and liquid; $\rho_{1}, \rho_{2}$ are densities of liquid and air.

Resonance curve for PVC sample in frequency range $10-140 \mathrm{~Hz}$ is presented in Fig. 3. The curve has several resonance peaks in frequency range of $10-40 \mathrm{~Hz}$ and a maximum peak corresponding to fundamental resonance frequency in the region of $113 \mathrm{~Hz}$. Fundamental resonant frequency can be changed by sample factor $(l / d)$

Similar resonance curves were obtained for PS, HDPE and LDPE. Density, form factor and thickness of the samples are presented in table 1 . Resonance curves in the region of principal resonant frequencies for each polymer at $293 \mathrm{~K}$ are presented in Fig. 4. The results of measurements $f_{r}, \Delta f_{r}$ are presented in table 1.

Analysis of obtained data shows that main resonant frequencies increase in a number of LDPE, HDPE, PS, PVC and lie in the range $105-113 \mathrm{~Hz}$. Accordingly, width varies from $8 \mathrm{~Hz}$ for LDPE to 12 for PS. For HDPE and PVC, $\Delta f_{r}$ value is $10 \mathrm{~Hz}$.

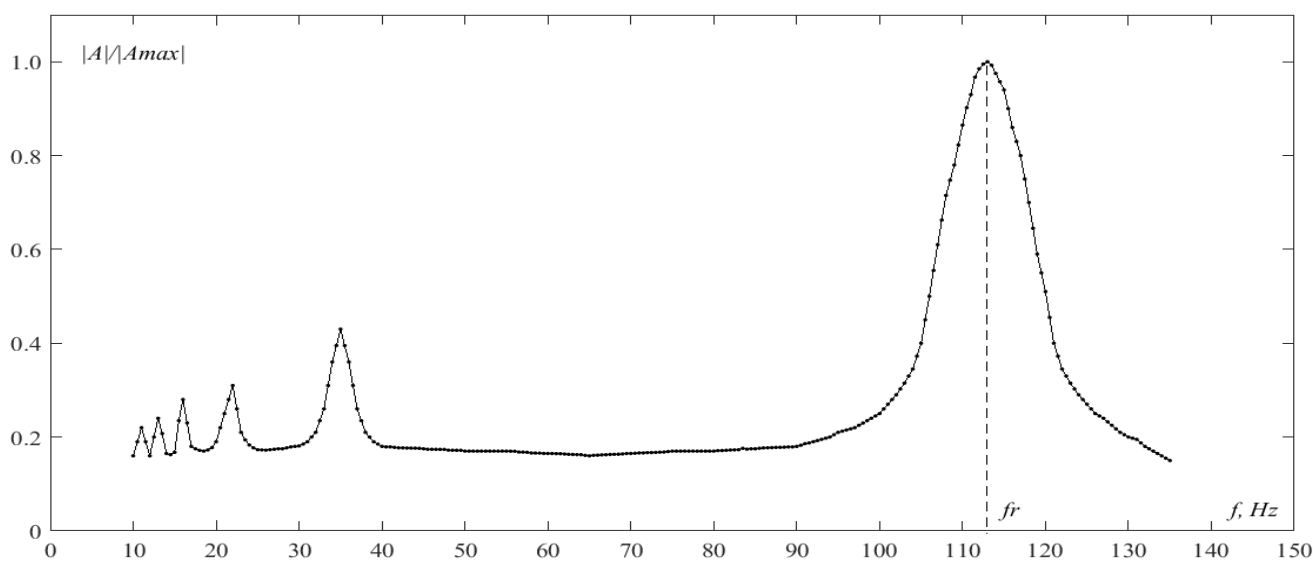

Fig. 4. Resonance curve for $\mathrm{PVC}$ in the frequency range $10-140 \mathrm{~Hz}$

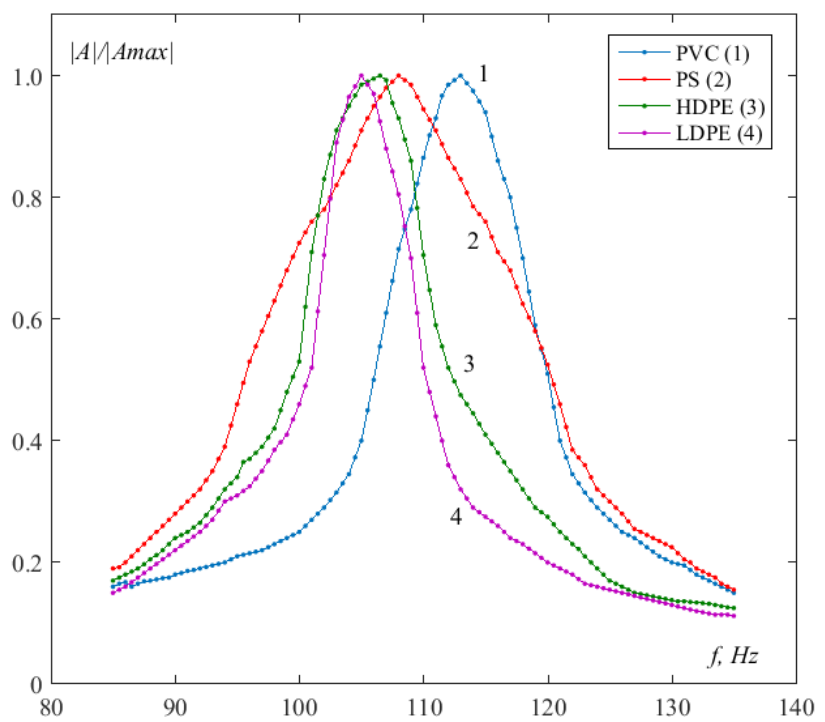

Fig. 5. Resonance curves for basic resonance frequencies for polymer samples: $1-P V C, 2-P S, 3-H D P E, 4-L D P E$.
The calculations of values of $E^{\prime}, \operatorname{tg} \delta, E^{\prime \prime}$ and $E^{*}$ by relations (14)-(17) are presented in table 1.

Magnitude of $E^{\prime}$ increases in a number of LDPE, HDPE, PS, $\mathrm{PVC}$ and lies in range $(2.24-3.56) \cdot 10^{9} \mathrm{~N} / \mathrm{m}^{2}$. The $\operatorname{tg} \delta$ value is minimal for LDPE 0.07 and increases to 0.11 for PS. For HDPE and PVC, mechanical loss factor is 0.09 . Similarly a change in value of $\operatorname{tg} \delta$ change values of $E^{\prime \prime}$. Values of Jung's $E^{*}$ complex modulus of a number of polymer materials follow tendency of changing its real part of $E^{\prime \prime}$.

Table 1. Measurement results

\begin{tabular}{|l|c|c|c|c|}
\hline \multirow{2}{*}{ Value } & \multicolumn{4}{c|}{ Polymers } \\
\cline { 2 - 5 } & PVC & PS & HDPE & LDPE \\
\hline$\rho, \mathrm{kg} / \mathrm{m}^{3}$ & 1396 & 1040 & 950 & 915 \\
\hline$l / d$ & 40.541 & 44.188 & 42.857 & 42.857 \\
\hline$d, \mathrm{~mm}$ & 0.74 & 0.66 & 0.70 & 0.70 \\
\hline$f_{r}, \mathrm{~Hz}$ & 113 & 108 & 106.5 & 105 \\
\hline$\Delta f_{r}, \mathrm{~Hz}$ & 10 & 12 & 10 & 8 \\
\hline$E^{\prime} \cdot 10^{-9}, \mathrm{~N} / \mathrm{m}^{2}$ & 3.55 & 3.04 & 2.40 & 2.24 \\
\hline$t g \delta$ & 0.09 & 0.11 & 0.09 & 0.07 \\
\hline$E^{\prime \prime} 10^{-8}, \mathrm{~N} / \mathrm{m}^{2}$ & 3.05 & 3.25 & 2.17 & 1.67 \\
\hline$E^{*} 10^{-9}, \mathrm{~N} / \mathrm{m}^{2}$ & 3.57 & 3.06 & 2.41 & 2.25 \\
\hline
\end{tabular}


Accuracy of installation is determined by an error in generator frequency settings as well as in determining density and dimensions of the sample. For the Siglent SDG1010, in frequency range $10-140 \mathrm{~Hz}$ the error does not exceed $10^{-5} \%$.

We estimate fractional error of $E^{\prime}$ value determination by following relation:

$$
\varepsilon_{E^{\prime}}=\varepsilon_{\rho}+4 \frac{\Delta l}{l}+2 \frac{\Delta d}{d}+2 \frac{\Delta f}{f_{r}}+\varepsilon_{\text {Const }},
$$

where $\varepsilon_{\rho}$ fractional error of a sample density measurement; $\Delta l, \Delta d$ maximum instrumental errors in measuring length and thickness of specimen; $\Delta f$ absolute error in determining fundamental resonant frequency; $\varepsilon_{\text {Const }}$ relative error in determining constants in ratio (14).

The fractional error of hydrostatic weighing method is $\varepsilon_{\rho}=0.2 \%$. The Fractional error of constants $\varepsilon_{\text {Const }}$ determination does not exceed $0.05 \%$.

Measuring samples thickness with up to $1.5 \%$, leads to determining fractional error of $E^{\prime}$ value.

An estimate of relative error $\varepsilon_{E^{\prime}}$ by relation (19) shows that it does not exceed $1.9 \%$.

Let us compare values of Young's modules by determining velocity of propagation of longitudinal ultrasonic waves (ultrasonic method), mechanical methods $[6,9]$ and vibrating reed method (Table 2).

Table 2. Young's modules of polymer materials are defined by different methods

\begin{tabular}{|l|c|c|c|}
\hline \multirow{2}{*}{ Polymer } & \multicolumn{3}{|c|}{$E \cdot 10^{-9}, \mathrm{~N} / \mathrm{m}^{2}$} \\
\cline { 2 - 4 } & $\begin{array}{c}\text { Ultrasonic } \\
\text { Method }\end{array}$ & $\begin{array}{c}\text { Vibrating-reed } \\
\text { method }\end{array}$ & $\begin{array}{c}\text { Mechanical } \\
\text { method }\end{array}$ \\
\hline LDPE & $4.3-4.4$ & 2.25 & 0.7 \\
\hline HDPE & $5.5-6.2$ & 2.41 & 0.8 \\
\hline PS & 5.7 & 3.06 & $3-3.5$ \\
\hline PVC & 7.4 & 3.57 & $2.4-3.1$ \\
\hline
\end{tabular}

Analysis of presented data shows that values of $E$ for a number of polymers determined by vibrating-reed method are smaller than values obtained by the ultrasonic method. For LDPE and PS on average 1.9 times, for HDPE respectively - 2.3-2.6 times, for PVC - 2.1. In this case, values of the Young's modulus determined by the vibrating-reed method are higher than those obtained by mechanical methods for LDPE, HDPE, PVC, respectively, 3.2 and 3 times and 1.2-1.5 times, respectively. For PS, value of $E$ coincides with lower bound and less than 0.9 times upper bound.

\section{Ph.D. Volodymyr Mashchenko}

e-mail: volodymyr_mashchenko@ukr.net

Doctoral student at the Odessa State Academy of Technical Regulation and Quality.

Main scientific direction - development of methods and instruments for measuring the physical and mechanical parameters of polymer materials.

ORCID ID: 0000-0001-6968-762X

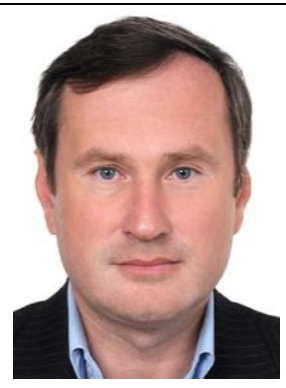

\section{Ph.D. Valentine Krivtsov}

e-mail: labor.relax@gmail.com

Associate Professor of Physics, Rivne State Humanitarian University, Department of Physics. Main scientific direction - spectroscopy of polymer materials.

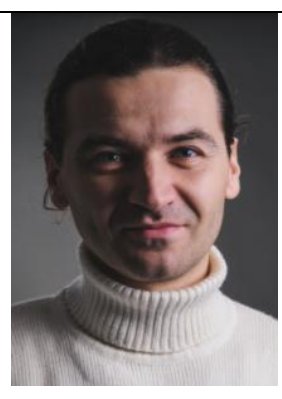

\section{Conclusion}

Experimental studies and comparative analysis showed that resonant vibration method has the prospects of technological application in metro-logical control bodies to create database of structural polymer materials. Usage of software to determine sample amplitude of oscillations in frequency range of measurement allows to minimize error in determining the fundamental resonant frequency. Error determination of Young's modulus of structural polymer materials is determined by measurements of sample geometric dimensions and depends on equipment instrumental error. Application of resonance vibrating method and analysis of resonance curve to control Young's modulus and mechanical loss factor at this stage is limited mainly by laboratory testing of polymer material samples. Implementation perspectives of the method are shown to investigate the influence of plastification, filling, radiation, orientation, heat treatment and other factors on viscoelastic properties of high-molecular mass compounds, and to define dependence between their static and dynamic properties.

\section{References}

[1] Caracciolo R., Gasparetto A., Giavagnoni M.: Application of causality check and the reduced variable method for experimental of Yong's modulus of viscoelastic matrial. Mechanic of materials 33/2001, 693-703.

[2] Ferry J. D.: Viscoelastic properties of polymers. John Wiley \& Sons Inc., New York/Chichester/Brisbane/Toronto/Singapore 1980

[3] Gamboa F., Corona J. E., Hoy-Benitez J.A., Aviles F., Oliva A. I., Sosa V Simple vibrating reed apparatus for determination of thin film elastic modulus. 1st International Congress on Instrumentation and Applied Sciences 2014 https://www.researchgate.net/publication/265975755_Simple_vibrating_reed_ap paratus_for_determination_of_thin_film_elastic_modulus (available: 15.09.2019)

[4] Kolupaev B. B., Krivtsov V. V., Malynovs'kiy E. V.: The acoustic spectroscopy of the PVC-based composition materials in audio frequency range. Acoustic bulletin 16(2)/2013-2014, 3-7.

[5] Lin K., Yu Y., Xi J., Li H., Guo Q., Tong J., Su L.: A Fiber-coupled self-nixing laser diode for the measurement of Young's modulus. Sensors 16, 2016, 928 [DOI: 10.3390/s16060928].

[6] Mashchenko V.: Determination of elasticity modules of constructional and heterogeous materials by ultrasonic method. Scientific notes $65,2019,165-169$.

[7] Pintelon R., Guillaume P., De Belder K., Rolain Y.: Measurement of Young's modulus via modal analysis experiment: a system identification approach. 13th IFAC Symposium on System Identification, 2003, 389-394.

[8] ISO 18437-1:2012 Mechanical vibration and shock - Characterization of the dynamic mechanical properties of viscoelastic materials - Part 1: Principles and guidelines, https://www.iso.org/standard/35585.html (available: 15.09.2019)

[9] The Engineering Toolbox http://www.engineeringtoolbox.com/youngmodulusd_417.html. (available: 15.09.2019).

\section{Prof. Volodymyr Kvasnikov}

e-mail:kvp@nau.udu.ua

President of Engineering Academy of Ukraine, Head of Computerized electrical systems and technologies department (NAU)

Main scientific direction - development of method and instruments for measuring mechanical quantitie and metro-logical support for measurement processes.

ORCID ID: 0000-0002-6525-9721

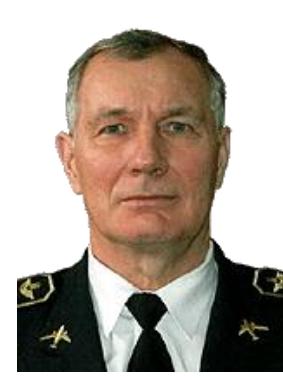

\section{Prof. Volodymyr Drevetskiy}

e-mail: westra@rv.ua.net

Vice president of Engineering Academy of Ukraine, Head of Automation, electrical and computerintegrated technologies department (NUWEE).

Main scientific direction - development of methods and devices for continuous automatic monitoring of physical and mechanical parameters of fluids and polymers materials.

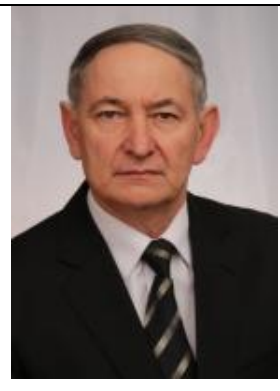

